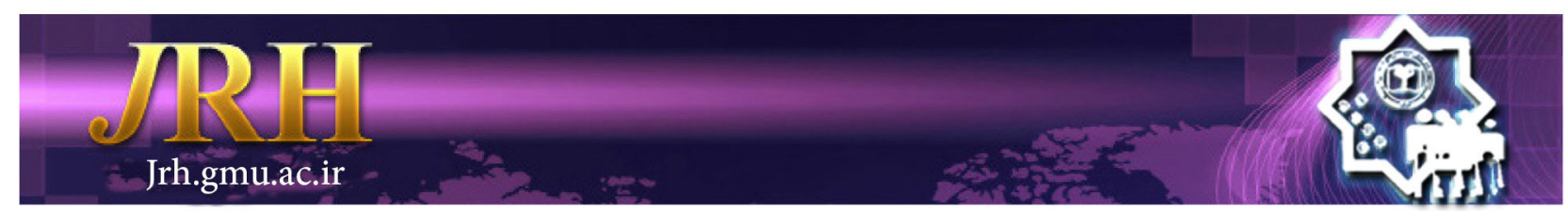

\title{
Factors affecting exclusive breastfeeding: theory of planned behavior
}

Zeynab Karimi ${ }^{1}$, Siamak Mohebi ${ }^{1}$, Narges Afshar ${ }^{2}$, Zabihollah

Gharlipour ${ }^{1}$

\begin{abstract}
1. Department of Health Education and Health Promotion, School of Health, Qom University of Medical Sciences, Qom, Iran 2. Department of Public Health, School of Health, Qom University of Medical Sciences, Qom, Iran

Correspondence to: Zabihollah Gharlipour, Department of Health Education and Health Promotion, School of Health, Qom University of Medical Sciences, Qom, Iran Email: gharlipourz@yahoo.com
\end{abstract}

Received: 6 Feb 2017

Accepted: 25 Oct 2017

How to cite this article: Karimi Z, Mohebi S, Afshar N, Gharlipour Z. Factors affecting exclusive breastfeeding: theory of planned behavior. J Research \& Health2019; 9(3): 275- 281.

\author{
Journal of Research \& Health
Social Development \& Health Promotion \\ Journal of Research \& Health
Social Development \& Health Promotion \\ Research Center \\ Vol. 9, No.3, May \& Jun 2019 \\ Pages: 275- 281 \\ DOI: $10.29252 / j$ rh.9.3.275 \\ Original Article
}

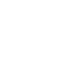

\section{Introduction}

In the first six months of life, breast milk fulfills all children's nutritional needs and plays a very important role in protecting children's health [1]. Exclusive Breastfeeding (EBF) is recommended by the World Health Organization (WHO) as a policy to increase child survival and reduce diseases in children living around the world. The WHO recommends all countries to promote and support EBF for children up to six months of age [2,3]. According to the WHO's definition, EBF is the practice of feeding the child aged less than six months old using breast milk alone, without water and other feeding materials except for medicines, vitamin, and authorized complements [4]. Breast milk is suggested as the best milk for infants. Therefore, one of the goals to achieve a healthy community by 2010 is to reach a breastfeeding rate of $75 \%$ [5]. According to previous studies carried out in Iran, the rate of breastfeeding varies from $23 \%$ to $47 \%[6,7]$. Based on previous studies, the rate of EBF in Iran was $45 \%$ in 2001 which changed to $28 \%$ in 2006 and it has a significant difference with the goals of WHO [8]. A retrospective study bout Breastfeeding in Iran showed that the breastfeeding rates at 4 and 6 months of age in rural areas were $58 \%$ and $29 \%$, and in urban areas $56 \%$ and $27 \%$, respectively [9]. In Nakhshab et al.,'s study, the prevalence of EBF up to six months of age was reported as $73 \%$ [10]. In recent years, a significant decrease in EBF has been observed in many industrialized countries; moreover, numerous studies carried out in industrialized countries, 
including the United States of America, have reported 3-6 fold increase in mortality of infants under one year of age who had not been breastfed. Accordingly, the American Academy have recommended the use of breast milk instead of formula [11]. According to some studies, the variables that may affect EBF and duration of breastfeeding are the followings: race, maternal age, mother's occupation, parents' education level, socioeconomic factors, insufficient breast milk, baby disease, maternal obesity, smoking, twining, type of delivery, and mothers' tendency for breastfeeding [12-15]. Breastfeeding behavior is influenced by various factors, including physiological and psychological status of mothers [16]. Making changes in physiological factors is difficult and sometimes impossible; therefore, to promote EBF behavior, it is necessary to study motivational and psychological factors [17-20]. The Theory of Planned Behavior (TPB) is one of the behavioral theories which can be utilized as a proper framework to examine mothers' EBF behavior. According to a meta analytic study, after reviewing other theories and models, the TPB is identified as the most complete and the most appropriate theory to study the behavior [21]. As this theory suggests, intention is under the influence of three independent constructs, including attitude, subjective norms, and perceived behavioral control. Regarding the TPB, when a person believes a behavior is positive, some influential people expect that behavior to happen, and has control over that specific behavior, he / she develops an intention to perform that behavior. Moreover, this theory assumes that the attitudes, subjective norms, and perceived behavioral control are determined by the underlying assumptions [22] Although several studies have been conducted on continued breastfeeding in developing countries, few studies have utilized an appropriate theoretical framework to examine the continuity of exclusive breast-feeding behavior [23-25]. Taking into consideration the abovementioned items, this study aimed to determine factors affecting EBF based on the TPB.

\section{Method}

This cross-sectional study aimed to determine factors affecting EBF based on TPB in Qom, Iran during 2016. The study population was consisted of lactating women (whose babies were six months old and younger, consistent with the WHO's definition of EBF). In this study, using multistage sampling method four regions were selected. Such that, four urban areas were considered as a category. Then, the health centers ( 22 health centers) in each category were considered as a cluster. Out of all health centers, 12 ones were selected randomly. Finally, the participants were chosen randomly from these centers using sample size formula. Based on Mohammad Beygi et al.'s study [26], the sample size was estimated 373 while $\alpha=0.05$ (confidence interval of $95 \%$ ), $p=$ $0.41, \mathrm{~d}=0.05$.

In order to collect the required data, we used EBF questionnaire that included questions about demographic items such as age of infant, gender of infant, gestational age at birth, infant's weight at birth, current weight of infant, type of pregnancy (intended or unintended pregnancy), method of delivery, number of children, mother's age, mother's education level, mother's job, father's education level, father's job, and household income levels (a total of 16 questions). The questionnaire also included questions about the TPB constructs, including attitude (11 items, with minimum and maximum scores of 11 and 55), subjective norms ( 7 items, with minimum and maximum scores of 7 and 35), perceived behavioral control (4 items, with minimum and maximum scores of 4 and 20), behavioral intention (3 items, with minimum and maximum scores of 3 and 15) and behavior ( 2 items, with minimum and maximum scores of zero and 2). It should be noted that these constructs were scored using a five-point Likert Scale, ranging from strongly agree to strongly disagree. The items on behavior were multiple-choice questions, and the correct answer was scored one point and the other options were scored zero. Alemi et al, [27] examined the reliability of this questionnaire using Cronbach's alpha coefficient and reported 
as such attitude $(\alpha=0.80)$, subjective norms $(\alpha=0.84)$, perceived behavioral control $(\alpha=0.75)$, behavioral intention $(\alpha=0.86)$ and totally, TPB $(\alpha=0.79)$; they also verified its validity through using face and content validity measures.

The aim of the project was explained to all the participants before initiating the study and all them were ensured about the confidentiality of their data. Obtaining informed consent, the selected participants were recruited for the study. The collected data were analyzed using SPSS-20 and running independent t-test, ANOVA, and Pearson relationship coefficient $(\mathrm{p}<0.05)$.

\section{Results}

The mean age of women was $26.59 \pm 5.39$ years and the mean age of infants was $3.03 \pm 1.60$ months. The mean birth weight of infants was $3220.04 \pm 453.34$ gram and their mean weight at the time of the study was $5678.58 \pm 2400$ gram. Based on the findings, $72 \%$ of mothers $(270$ people) were feeding their babies exclusively with breast milk and they did not use any other type of food to feed their children. In addition, the results of current study showed no statistically significant relationship between EBF behavior and gender of infant, gestational age at birth, infant's weight at birth, current weight of infant, type of pregnancy (intended or unintended pregnancy), method of delivery, the time interval between the two deliveries, number of children, mother's age, mother's education level, and mother's job $(p>0.05)$. However, EBF behavior had a

Table 1 The relationship between demographic variables and EBF behavior

\begin{tabular}{|c|c|c|c|c|}
\hline Variable & & Frequency $(\%)$ & EBF behavior (Mean \pm SD) & $\mathrm{p}$ \\
\hline \multirow{2}{*}{ Gender of infant } & Male & $172(46.1)$ & $77.32 \pm 34.33$ & \multirow{2}{*}{$\begin{array}{c}\mathrm{p}=0.21 \\
\mathrm{t}=-1.23\end{array}$} \\
\hline & Female & $201(53.9)$ & $81.59 \pm 32.16$ & \\
\hline \multirow{2}{*}{$\begin{array}{l}\text { Type of } \\
\text { pregnancy }\end{array}$} & Intended & $324(86.9)$ & $80.86 \pm 32.27$ & \multirow{2}{*}{$\begin{array}{l}\mathrm{p}=0.06 \\
\mathrm{t}=1.82\end{array}$} \\
\hline & Unintended & $49(13.1)$ & $71.42 \pm 38.18$ & \\
\hline \multirow{2}{*}{$\begin{array}{l}\text { Method of } \\
\text { delivery }\end{array}$} & Normal & $198(53.1)$ & $80.80 \pm 32.81$ & \multirow{2}{*}{$\begin{array}{l}\mathrm{p}=0.42 \\
\mathrm{t}=0.76\end{array}$} \\
\hline & Caesarean section & $175(46.9)$ & $78.28 \pm 33.68$ & \\
\hline \multirow{2}{*}{ Nationality } & Iranian & $349(93.6)$ & $80.08 \pm 33.05$ & \multirow{2}{*}{$\begin{array}{l}\mathrm{p}=0.35 \\
\mathrm{t}=1.02\end{array}$} \\
\hline & Non Iranian & $24(6.4)$ & $72.91 \pm 36.05$ & \\
\hline \multirow{5}{*}{$\begin{array}{l}\text { Father's } \\
\text { educational level }\end{array}$} & Illiterate & $2(0.5)$ & $100.00 \pm 0.01$ & \multirow{5}{*}{$\begin{array}{l}\mathrm{p}=0.04 \\
\mathrm{~F}=2.43\end{array}$} \\
\hline & Primary school & $43(11.5)$ & $87.20 \pm 31.03$ & \\
\hline & Junior high school & $76(20.4)$ & $86.84 \pm 26.29$ & \\
\hline & Diploma & $117(31.4)$ & $76.49 \pm 34.47$ & \\
\hline & Academic degree & $135(36.2)$ & $75.55 \pm 35.54$ & \\
\hline \multirow{6}{*}{ Father's job } & Unemployed & $8(2.1)$ & $93.75 \pm 17.67$ & \multirow{6}{*}{$\begin{array}{l}\mathrm{p}=0.02 \\
\mathrm{~F}=2.68\end{array}$} \\
\hline & Self-employed & $171(45.8)$ & $82.45 \pm 32.75$ & \\
\hline & Worker & $52(13.9)$ & $85.57 \pm 24.92$ & \\
\hline & Employee & $41(11)$ & $69.51 \pm 40.12$ & \\
\hline & Farmer & $4(1.1)$ & $100.00 \pm 0.01$ & \\
\hline & Other & $97(26)$ & $73.71 \pm 34.68$ & \\
\hline \multirow{5}{*}{$\begin{array}{l}\text { Mother's } \\
\text { educational level }\end{array}$} & Illiterate & $5(1.3)$ & $90.00 \pm 22.36$ & \multirow{5}{*}{$\begin{aligned} \mathrm{p} & =0.06 \\
\mathrm{~F} & =2.38\end{aligned}$} \\
\hline & Primary school & $36(9.7)$ & $83.33 \pm 33.80$ & \\
\hline & Junior high school & $73(19.6)$ & $82.19 \pm 30.47$ & \\
\hline & Diploma & $165(44.2)$ & $82.42 \pm 31.62$ & \\
\hline & Academic degree & $94(25.2)$ & $70.74 \pm 36.96$ & \\
\hline \multirow{4}{*}{ Mother's job } & Housewife & $342(91.7)$ & $79.82 \pm 32.97$ & \multirow{4}{*}{$\begin{array}{l}\mathrm{p}=0.51 \\
\mathrm{~F}=0.76\end{array}$} \\
\hline & Self-employed & $4(1.1)$ & $100.00 \pm 0.01$ & \\
\hline & Employee & $12(3.2)$ & $75.00 \pm 39.88$ & \\
\hline & Other & $15(4)$ & $73.33 \pm 37.16$ & \\
\hline
\end{tabular}


significant relationship with father's educational level and father's job $(\mathrm{p}<0.05)$ (Table 1).

As shown in Table 3 , subjective norms ( $\mathrm{p}=0.007$, $\mathrm{r}=-0.13)$ and intention $(\mathrm{p}=0.001, \mathrm{r}=-0.39)$ had significant negative relationships with $\mathrm{EBF}$ behavior. However, attitudes and perceived behavioral control had no significant relationship with EBF behavior ( $p>0.05)$.

Table 3: The relationship between the TPB constructs and EBF behavior

\begin{tabular}{lccccc}
\hline Variable & Attitude & $\begin{array}{c}\text { Subjective } \\
\text { norms }\end{array}$ & $\begin{array}{c}\text { Perceived } \\
\text { behavioral control }\end{array}$ & Intention & $\begin{array}{c}\text { EBF } \\
\text { behavior }\end{array}$ \\
\hline Attitude & 1 & & & & \\
Subjective norms & $\begin{array}{c}\mathrm{p}=0.001 \\
\mathrm{r}=0.26\end{array}$ & 1 & & & \\
Perceived behavioral & $\mathrm{p}=0.001$ & $\mathrm{p}=0.003$ & 1 & & \\
control & $\mathrm{r}=0.16$ & $\mathrm{r}=0.13$ & & 1 & \\
Intention & $\mathrm{p}=0.213$ & $\mathrm{p}=0.001$ & $\mathrm{p}=0.856$ & 1 \\
& $\mathrm{r}=0.06$ & $\mathrm{r}=0.41$ & $\mathrm{r}=-0.09$ & & \\
EBF behavior & $\mathrm{p}=0.692$ & $\mathrm{p}=0.007$ & $\mathrm{p}=0.064$ & $\mathrm{p}=0.001$ & 1 \\
\hline
\end{tabular}

\section{Discussion}

With respect to the results of the present study, subjective norms and behavioral intention had a significant negative relationship with EBF behavior. The two factors of subjective norms and behavioral intention were the determinant factors that affect EBF behavior. Various studies have reported a variety of reasons and factors hindering EBF, including low knowledge, lack of support from husbands, and mothers' negative attitude toward EBF [28,29] preventing mothers to adopt EBF behavior. According to some other studies, other people's comments were introduced as the major factor inhibiting mothers from EBF [25,30] that is consistent with our results which indicated and confirmed the influence of subjective norms and behavioral intention in the continuity of EBF behavior. Increased support from other people, including husband, family members, friends, and health personnel can have a considerable impact on mothers' behavior. The positive effects of subjective norms and intention and the role of families and friends must be considered and strengthened so that to reduce their negative effects on EBF behavior. As Mehrparvar et al, [30] showed, lack of emotional support from family and friends and their incorrect comments for caring the baby can reduce maternal self-esteem and destabilize mothers. It is necessary to educate families, especially spouses, so that they support mothers to practice breastfeeding. In our study, behavioral intention had a significant negative relationship with behavior; of course, it should be kept in mind there is not always a linear and direct relationship between behavioral intention and behavior and there may be some factors other than those stated by the TPB. As noted earlier, external factors, such as the comments by other people, can play a role in changing an intention into a behavior; however, further studies are needed to detect and evaluate their effects. Concerning the other constructs of the TPB, attitude and perceived behavioral control had no significant relationship with EBF behavior that is inconsistent with the results of previous studies revealing a significant and positive relationship between mother's attitude and continuity of EBF behavior [28,29].

Further studies are suggested to investigate. The significant positive relationship between perceived behavioral control and the two constructs of attitude and subjective norms can indicate the structural relationship between these constructs and denotes their impact on each other. In addition, behavioral intention showed a significant and positive relationship with subjective norms; the existence of this relationship can justify the significant 
and positive relationship between behavioral intention and $\mathrm{EBF}$ behavior. According to Ziai et al., mothers' false beliefs, ignorance, and misconception regarding the adequacy of breastfeeding were the most important factors contributing to the failure of EBF [28]. Previous studies also have shown that mother's ignorance, attitude toward breastfeeding, subjective norms, and views toward the consequences of breastfeeding are associated with mother's breastfeeding intention [29-32]. Based on the results of this study, the rate of EBF behavior among mothers who referred to health centers in Qom was $72 \%$ that is almost close to the EBF rate recommended by the WHO by 2010 (i.e. 75\%) and healthy society targets [6]. The rate observed in our study was higher than rates reported by Mohammad Beygi et al. [26] and Almasi et al. [31]. In Mehrparvar et al.'s study [30], 98.4\% of children who aged less than 6 months were fed non-exclusively, while in our study the rate of non-exclusive feeding was $27.6 \%$ indicating the higher rate of EBF behavior in Qom. According to the results of Pasha et al.'s study, among all newborns who were exclusively breastfeed within the first 60 minutes after birth, $78 \%$ of infants benefited from the continuity of breastfeeding until the 24th month of age. This study investigated the role of EBF in the first hours after birth and its impact on continuity of breastfeeding [33]. Different studies have reported different rates of EBF behavior; for instance, it was reported 21\% in Japan, $7.8 \%$ in India, and 6\% in Canada [31]. The differences in the observed rates indicate the effect of different cultural, economic, geographic, political, and individual factors on the continuation of this behavior. In our study, the individual factors of father's education and occupation significantly affected EBF behavior; however, mother's education and occupation had no significant relationship with the studied behavior. In contrast to our results, Bhandari et al. reported a significant relationship between EBF and mother's occupation and education EBF [25] but not a significant relationship between EBF and other factors. In our study, the majority of mothers were housewives and had a high school diploma or higher educational degree; however, their education level was not significantly associated with EBF behavior that is in line with Ziai et al, [25] and Mohammad Beygi et al, [26]. The difference in the results of previous studies may be attributed to not only the personal, cultural, economic, and regional factors but also the time of the study. It represents the influence of several factors which act as the motivators or inhibitors affecting the continuity of EBF behavior. Therefore, it might be concluded that the significant relationship between father's education and EBF is affected by the contextual factors as well.

\section{Conclusion}

The results of this study represented the effect of subjective norms and behavioral intension (as the constructs of the TPB) on EBF. As a result, intervention programs using the TPB can be helpful for promoting the continuity of EBF.

\section{Contribution}

Study design: NA, ZG, SM

Data Collection and Analysis: ZK

Manuscript preparation: ZG, ZK, SM

\section{Acknowledgments}

This study was approved by the Research Committee ofQomUniversity ofMedical Sciences (Ethical Code: IR.MUQ.REC.1394.140). The authors would like to express their thanks to honorable authorities of research committee of Qom university of medical sciences, esteemed principals of health centers, and the women who participated in our study

\section{Conflict of Interest}

"The authors declared that they have no competing interests."

\section{Funding}

The authors received financial support (Project Code: 16951/34/P) for the research from the research deputy of Qom University of Medical Sciences. 


\section{References}

1- Walker A. Breast milk as the gold standard for protective nutrients. J Pediatr2010; 156(2): 3-7.

2- World Health Organization. The optimal duration of EBF: report of an expert consultation. Geneva, Switzerland: World Health Organization; 2001.

3- Sinusas K, Gagliardi A. Initial management of breastfeeding. Am Fam Physician2001; 64(6): 981-8.

4- Ghanbarnejad A, Abedini S, Taqipoor L. Exclusive breastfeeding and its related factors among infants in Bandar Abbas city, Iran. Journal of Babol University of Medical Sciences2014; 16(1): 85-91.

5- US Department of Health, Human Services. United States department of health and human services: healthy people 2010: understanding and improving health. Washington (DC): US Government Printing Office; 2000. pp:15-20.

6- Hatami A, Talebi Toti Z. Patterns of breastfeeding in infants. Journal of Hayat2007; 13(2): 71-6.

7- Ghaed Mohammadi Z, Zafarmand MH, HeidariGhR, Anaraki A, Dehghan A. Determination of effective factors in breast-feeding continuity for infants less than 1 year old in Urban Area of Bushehr province. Iranian South Medical Journal2004; 7(1): 79-87.

8- Veghari G, Mansourian A, Abdollahi A. Breastfeeding status and some related factors in northern Iran. Oman Med J2011; 26(5): 342-8.

9- Olang B, Farivar K, Heidarzadeh A, Strandvik B, Yngve A. Breastfeeding in Iran: prevalence, duration and current recommendations. Int Breastfeed J 2009; 4(1): 8. 10- Nakhshab M, Ghaffari J, Nasehi MM, YazdaniCharati J, Shakeri A, Nazari Z. Knowledge of general practitioners (GP) about characteristics of breastfeeding. Journal of Babol University of Medical Sciences2014; 16(7): 71-6.

11- Imani M, Mohammadi M, Rakhshani F, Shafie S. Breast feeding and its related factors in Zahedan. Journal of Kashan University of Medical Sciences (FEYZ)2003; 7(2): 26-33.

12- Thulier D, Mercer J. Variables associated with breastfeeding duration. J Obstet Gynecol Neonatal Nurs2009; 38(3): 259-68.

13- Labarere J, Gelbert-Baudino N, Ayral AS, et al. Efficacy of breastfeeding support provided by trained breastfeeding support provided by trained clinicians during an early, routine, preventive visit: a prospective, randomized, open trial of 226 mother-infant pairs. Pediatrics2005; 115(2):139-46.

14- Law SM, Dunn OM, Wallace LM, Inch SA. Breastfeeding best start study: training midwives in a 'hands off' positioning and attachment intervention. Matern Child Nutr2007; 3(3): 194-205.

15- Shamberger R. Breast feeding associated with reduced sudden infant death syndrome and infant mortality. Med $J$
Obstet Gynecol2014; 2(1): 1021.

16- Blyth RJ, Creedy DK, Dennis CL, et al. Breastfeeding duration in an Australian population: the influence of modifiable antenatal factors. $J$ Hum Lact2004; 20(1): 30-8.

17- Otsuka K, Dennis CL, Tasuoka H, Jimba M. The relationship between breastfeeding self-efficacy and perceived insufficient milk among Japanese mothers. $J$ Obstet Gynecol Neonatal Nurs2008; 37(5): 546-55.

18- Wells KJ, Thompson NJ, Kloeblen-Tarver AS. Development and psychometric testing of the prenatal breastfeeding self-efficacy scale. Am J Health Behav2006; 30(2): 177-87.

19- Julvez J, Ribas-Fitó N, Torrent M, Forns M, GarciaEsteban R, Sunyer J. Maternal smoking habits and cognitive development of children at age 4 years in a population-based birth cohort. Int J Epidemiol2007; 36(4): 825-32.

20- O'Brien M, Buikstra E, Hegney D. The influence of psychological factors on breastfeeding duration. $J A d v$ Nurs2008; 63(4): 397- 408.

21- Armitage CJ, Conner M. Efficacy of the theory of planned behavior: a meta-analytic review. $\mathrm{Br} J$ Soc Psychol2001; 40(4): 471-99.

22-Ajzen I. Behavioral intervention based on the theory of planned behavior. 2006, Avalabe at: http://people. umass.edu/aizen/pdf/tpb.intervention.pdf. Accessed Nov 16, 2016.

23- Penny ME, Creed-Kanashiro HM, Robert RC, Narro MR, Caulfield LE, Black RE. Effectiveness of an educational intervention delivered through the health services to improve nutrition in young children: a cluster-randomised controlled trial. The Lancet2005; 365(9474): 1863-72.

24- Santos I, Victora CG, Martines J, et al. Nutrition counseling increases weight gain among Brazilian children. J Nutr2001; 131(11): 2866-73.

25- Bhandari N, Mazumder S, Bahl R, et al. An educational intervention to promote appropriate complementary feeding practices and physical growth in infants and young children in rural Haryana. $J$ Nutr2004; 134(9): 2342-8.

26- Mohammad Beygi A, Mohammad Salehy N, Bayati A. The pattern of exclusive breast feeding in referred neonatal to health centers of arak. Journal of Guilan University of Medical Sciences2009; 18(70): 17-25.

27-Alami A, Moshki M, Alimardani A. Development and validation of theory of planned behavior questionnaire for exclusive breastfeeding. Journal of Neyshabur University of Medical Sciences2014; 2(4): 45-53.

28- Ziaie T, Ghanbari A, Hassanzadeh Rad A, Yazdanipour MA. Investigating risk factors of failure in exclusive breastfeeding in less than one-yearold children referred to health centers in Rasht city. 
The Iranian Journal of Obstetrics, Gynecology and Infertility 2012; 15(18): 32-9.

29-Mohammadi Zeidi I, Pakpour Hajiagha A, Mohammadi Zeidi B. Effectiveness of educational intervention on exclusive breast feeding in primipara women: application of planned behavior theory. Razi Journal of Medical Sciences2015; 21(127): 12-23.

30-Mehrparvar S, Varzandeh M. Investigation of decreasing causes of exclusive breast feeding in children below six months old, in Kerman city during 2008- 2009. Journal of Fasa Univercity of Medical Science2011; 1(1): 45-52.

31- Almasi H, Saberi HR, Moravveji AR. The pattern of exclusive breast feeding in neonates under healthcares in health centers of Kashan city during 2006. Feyz Journal of Kashan University of Medical Sciences2010; 14(2): 163-8.

32- Heydarpour S, Golboni F, Heydarpour F, Timareh M. Factors associated with exclusive breastfeeding in Kermanshah in 2007. Journal of Kermanshah University of Medical Science 2011; 15(3): 227-30

33- Zahed Pasha E, Zenoozi F, Baleghi M, Bijani A, Zahed Pasha Y. Association of breastfeeding in the first hours of life with duration of lactation. Babol University of Medical Sciences2012; 14(6):17-24.

\footnotetext{
Copyright(C) 2016 ASP Ins. This open-access article is published under the terms of the Creative Commons Attribution-NonCommercial 4.0 International License which permits Share (copy and redistribute the material in any medium or format) and Adapt (remix, transform, and build upon the material) under the Attribution-NonCommercial terms.
} 